\title{
Canadian volunteers
}

\author{
Lloyd R Sutherland MD FACP FRCPC
}

A

$\mathrm{s}$ the countdown begins, with less than 24 months before the opening ceremonies of the World Congress of Gastroenterology, let us reflect upon the important contributions that volunteers make to such an activity. It was my good fortune to be in Calgary at the 1988 Olympics and to be involved, albeit in a very minor role, in the event. Soon Vancouver will host the games, and once again it will be for the most part a volunteer-organized event. That is how we do things in Canada.

For gastroenterologists, the next opportunity to play a role in another world-class event will be the World Congress of Gastroenterology in 2005. At the core of the organization is a group of volunteers, ably assisted by a small administrative staff. This group has already invested a great deal of time and effort to organize the best World Congress of Gastroenterology ever.

As I grow older (I will be 55 this year), I have come to realize how precious time is. You cannot manufacture time, you cannot recycle it, and you make choices every time you allocate it. Members of the Organizing Committee believe that the Congress is so important, they have taken time away from administrative, research, practice and personal activities.

So why does it seem that the same people show up on the Organizing Committee year after year? I think it is the same as in professional football and hockey, where coaches seem to rotate from one team to another. There appears to be only a small cadre of individuals with the chutzpah to be able to manage a professional team or organize an international meeting.
Why do they do it? Well, probably, for many it is a matter of pride that the Congress will be held in Canada. We all want it to be a success. The Canadian Association of Gastroenterology (CAG) may benefit both economically and scientifically from such an event.

I know that physicians (even gastroenterologists) often think of World Congress work as nothing more than an excuse for international travel. I often hear members fret about the travel costs associated with Gastro '99. I don't know what the costs were, but I do know that Gastro '99 had the highest attendance of any Pan-American Congress of Gastroenterology. Are the two related? I think so. In many societies, the strength of an invitation is based in part on the stature and credibility of the person presenting the invitation.

Recently, I overheard my assistant talking with a friend who commented that Dr Sutherland has such a glamorous life, flying all over the world, to which my assistant replied, "Glamorous, right! He takes a taxi to the airport, flies overnight to another city, goes to the hotel, gives the talk and flies home."

Now, that is not always the case, and travel can be fun, but the CAG membership should be assured that any travel to promote the Congress will follow CAG guidelines. These will be published in the Journal once they are through the CAG review process. The guidelines are currently in their sixth version, guys, get a life!!

Once again, volunteerism, a Canadian fact. 


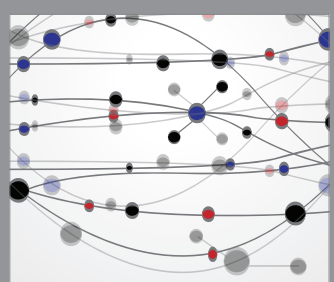

The Scientific World Journal
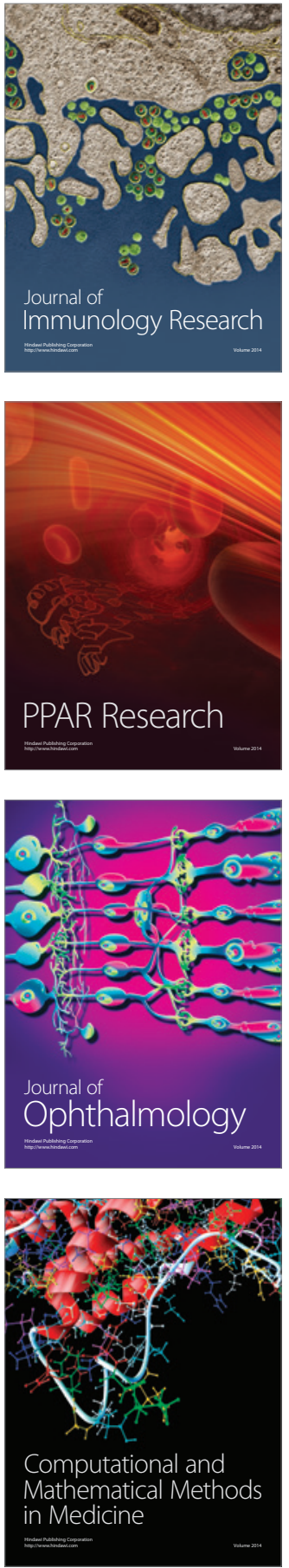

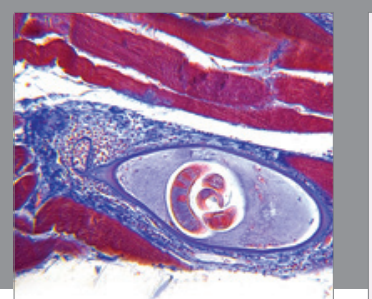

Gastroenterology Research and Practice

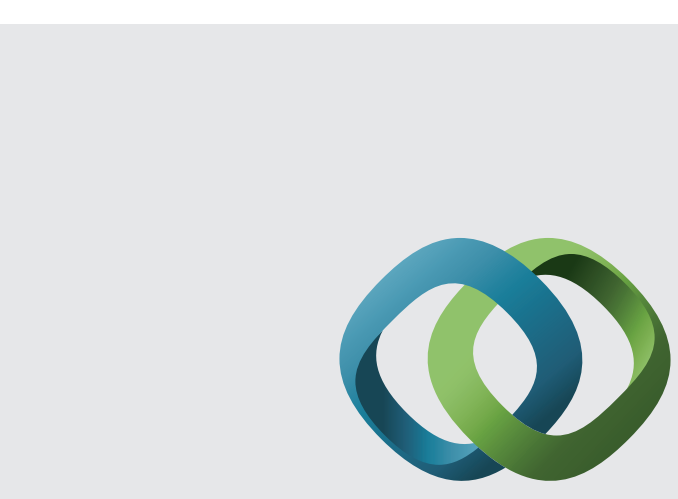

\section{Hindawi}

Submit your manuscripts at

http://www.hindawi.com
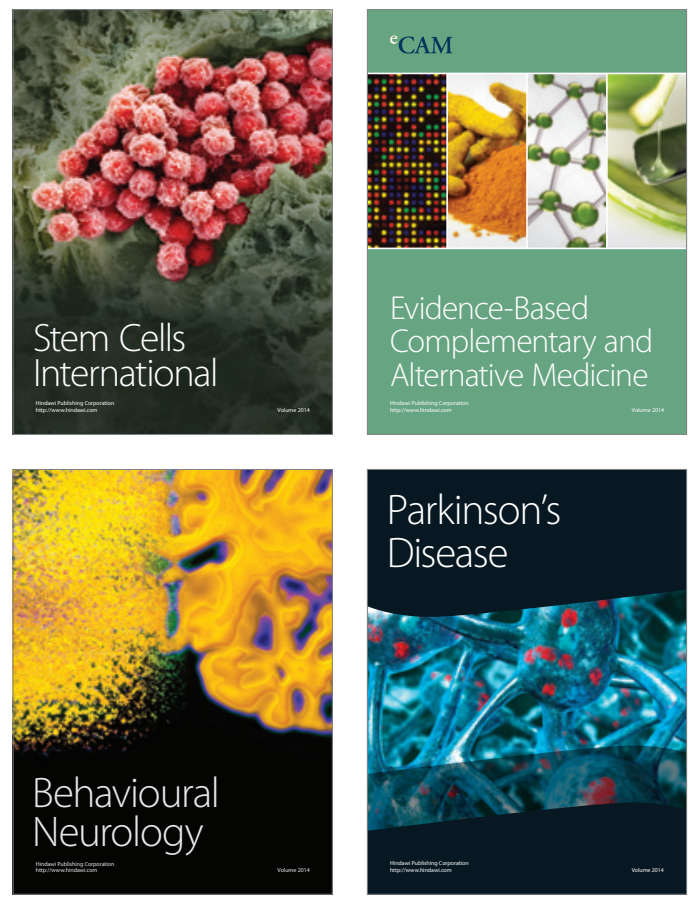
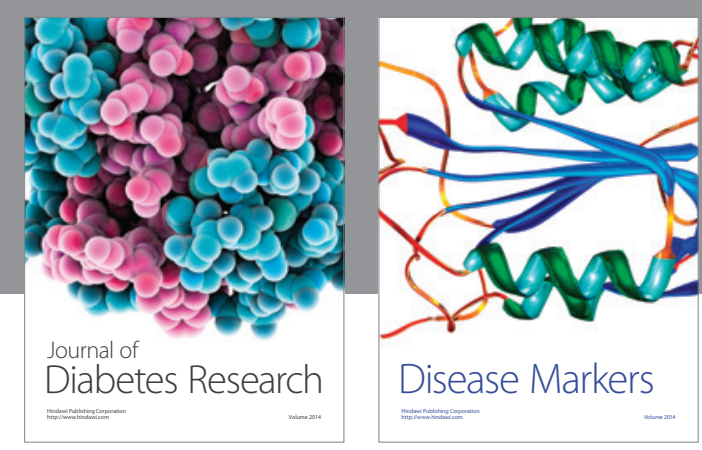

Disease Markers
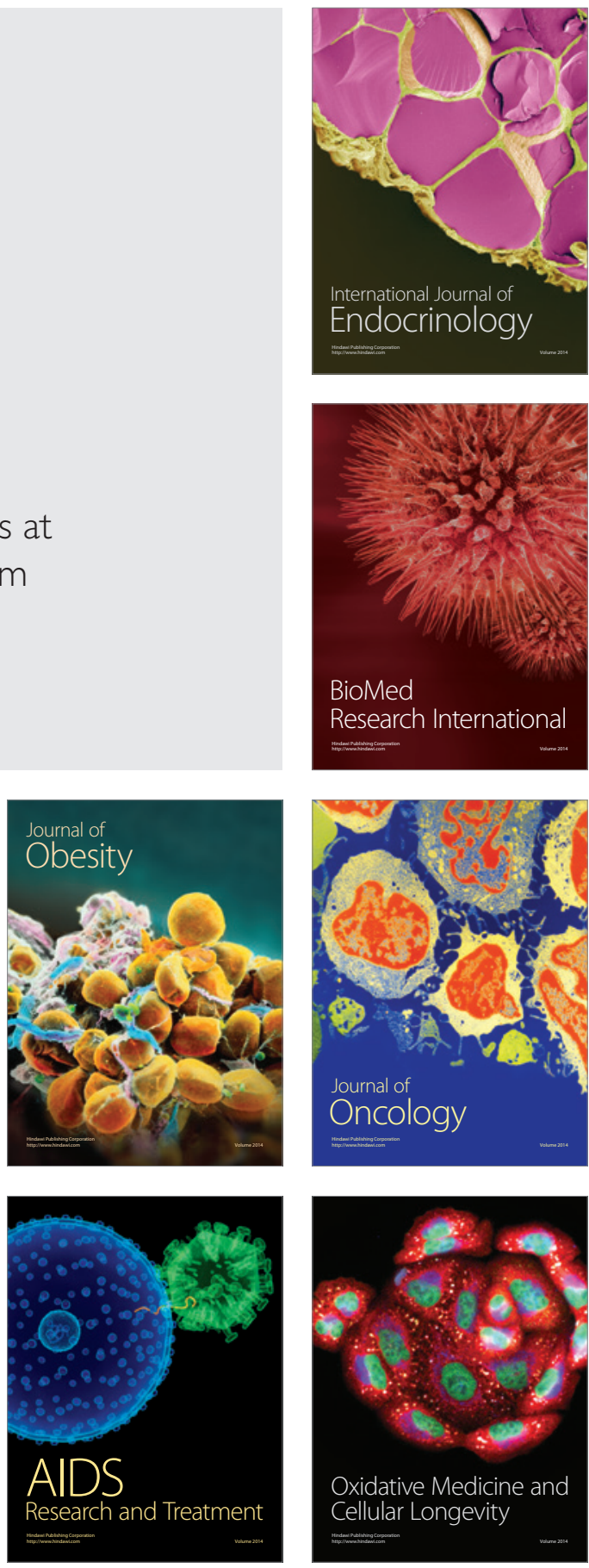